\title{
THE LARGE SCALE STRUCTURE OF THE UNIVERSE
}

Edited by M. S. LONGAIR and J. EINASTO
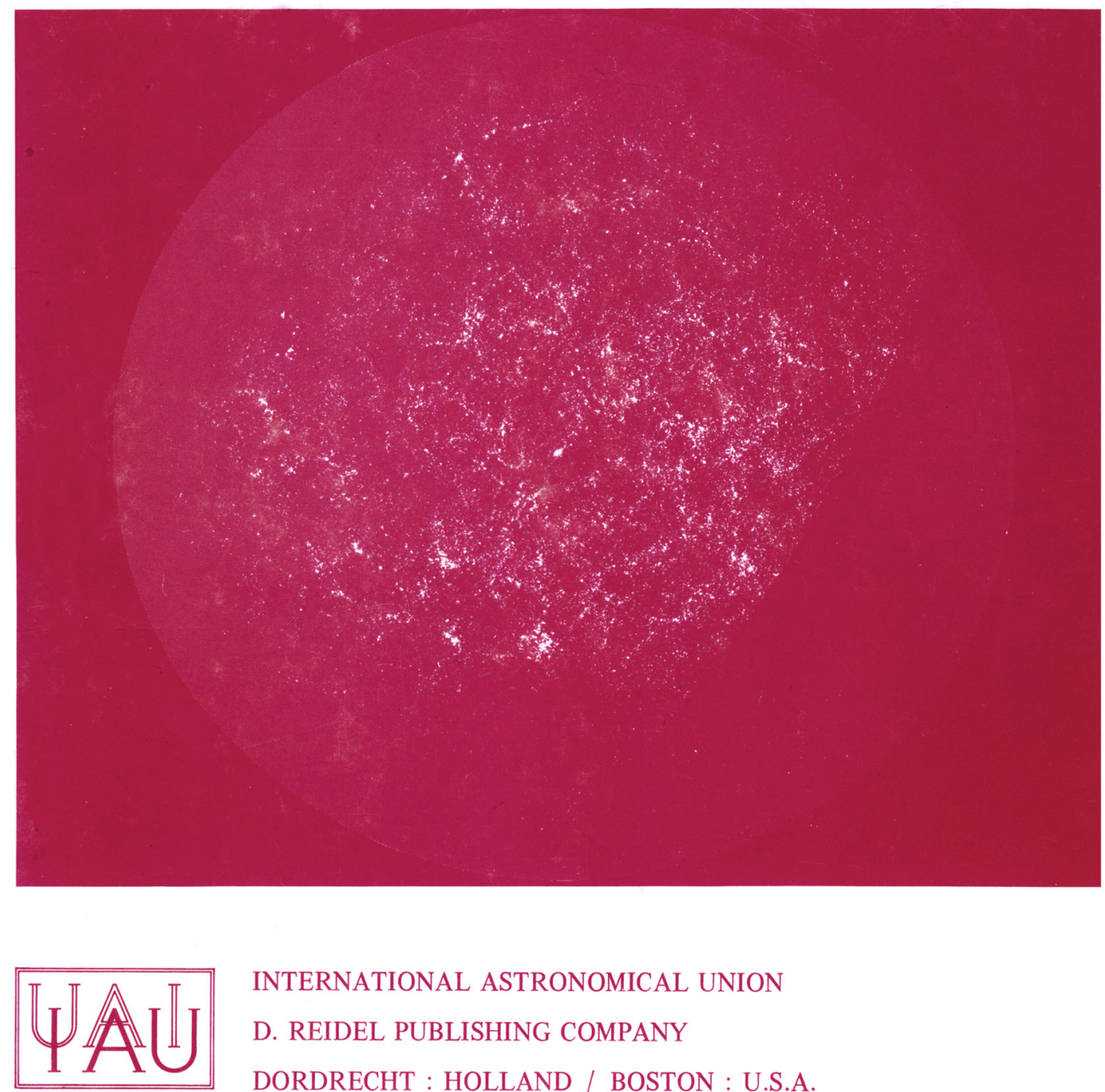

INTERNATIONAL ASTRONOMICAL UNION

D. REIDEL PUBLISHING COMPANY

DORDRECHT : HOLLAND / BOSTON : U.S.A. 


\section{THE LARGE SCALE STRUCTURE OF THE UNIVERSE}

SYMPOSIUM No. 79

The subject of the symposium included systems of galaxies of all scales from binary galaxies through groups, clusters, superclusters to the very largest structures in the observable Universe. The conference was divided into five sections in which the following subjects were treated in depth: 1. galaxies in small groups, 2. clusters of galaxies, 3. large scale systems, 4. observational evidence for cosmological evolution, and 5. the formation of structure in the Universe. In the first three sections the theory of these systems was discussed in the context of the most recent observational data. The direct observational evidence for cosmological evolution of large scale structures is still sparse, but related studies of the evolution of quasars and radio sources were discussed, as well as future observations which will advance understanding of this problem. A wide range of theories of the origin of structure in the Universe were described.

The symposium indicated how there is now considerable agreement among observers about the essential features of the large scale structure of the Universe. The problem areas were highlighted and the directions for future research outlined.

Cover: Picture of the Northern Galactic Hemisphere from Astronomical Journal 82, p. 249. Reproduced by permission. 
THE LARGE SCALE STRUCTURE OF THE UNIVERSE 


\title{
INTERNATIONAL ASTRONOMICAL UNION
}

UNION ASTRONOMIQUE INTERNATIONALE

\author{
SYMPOSIUM No. 79
}

HELD IN TALLINN, ESTONIA, U.S.S.R., SEPTEMBER 12 - 16, 1977

\section{THE LARGE SCALE STRUCTURE \\ OF THE UNIVERSE}

EDITED BY

'M. S. LONGAIR

Mullard Radio Astronomy Observatory, Cavendish Laboratory, Cambridge, England

AND

J. EINASTO

W. Struve Astrophysical Observatory of Tartu, Tôravere, Estonia, U.S.S.R.

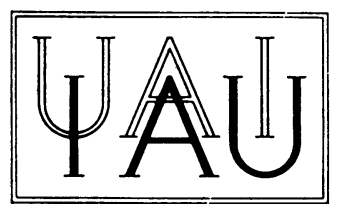

D. REIDEL PUBLISHING COMPANY

DORDRECHT : HOLLAND / BOSTON : U.S.A.

1978 
Library of Congress Cataloging in Publication Data

Main entry under title:

The large scale structure of the universe.

(Symposium - International Astronomical Union; no. 79)

Bibliography: $p$.

Includes index.

1. Cosmology - Congresses. 2. Galaxies - Congresses. 3. Stars-Clusters Congresses. I. Longair, M. S., 1941-

II. Einasto, Jaan.

III. Series:

International Astronomical Union. Symposium; no. 79.

QB981.L3 523.1

78-7032

ISBN 90-277-0895-9

ISBN 90-277-0896-7 pbk.

\author{
Published on behalf of \\ the International Astronomical Union \\ by \\ D. Reidel Publishing Company, P.O. Box 17, Dordrecht, Holland
}

All Rights Reserved

Copyright (C) 1978 by the International Astronomical Union

\author{
Sold and distributed in the U.S.A., Canada, and Mexico \\ by D. Reidel Publishing Company, Inc. \\ Lincoln Building, 160 Old Derby Street, Hingham, \\ Mass. 02043, U.S.A.
}

No part of the material protected by this copyright notice may be reproducea or utilized in any form or by any means, electronic or mechanical, including photocopying, recording or by any informational storage and retrieval system, without written permission from the publisher

Printed in The Netherlands 
TABLE OF CONTENTS

Foreword

$\mathrm{xi}$

Organising Committees

xiii

List of Participants

$\mathrm{xv}$

In the table of contents Invited Lectures are shown in block capitals, Contributed Papers in lower case, and Short Communications in indented lower case format.

\section{GALAXIES IN SMALL GROUPS}

B. A. VORONTSOV-VELYAMINOV: THE PHOTOGRAPHY OF GROUPS OF GALAXIES

I. D. KARACHENTSEV: VELOCITY DISPERSION IN SMALL SYSTEMS OF GALAXIES

E. L. TURNER: OPTICAL STUDIES OF SMALL GROUPS OF GALAXIES 21

R. B. TULLY and J. R. FISHER: NEARBY SMALL GROUPS OF GALAXIES 31

W. K. Huchtmeier: Observations of high velocity HI clouds in the Local Group

J. EINASTO: HYPERGALAXIES

J. R. GOTT, III: N-BODY SIMULATIONS AND THE VALUE OF $\Omega$

G. A. TAMMANN and R. KRAAN: THE GALACTIC NEIGHBOURHOOD

J. Materne: Three dimensional analysis of groups of galaxies

D. J. Hegyi: Detection of an optical halo surrounding the spiral galaxy NGC 4565

J. Einasto: The scatter in mass-to-1uminosity ratios

L. M. Ozernoy and M. Reinhardt: Stabilization of systems of galaxies by subclustering

C. Casini and J. Heidmann: Morphological investigation of pairs containing Markarian galaxies 
K.-H. Schmidt: Cluster membership of Seyfert galaxies

A. Tomov: The results of observations of double galaxies in the UBV system

I. Pronik and L. Metik: On the origin and evolution of pairs of galaxies that have different physical and kinematic characteristics

E. Khachikian: Markarian galaxies with double and multiple nuclei

W. Högner and N. Richter: Equidensitometric determination of angular diameters and mean surface magnitudes of compact galaxies

A. TOOMRE: INTERACTING SYSTEMS

B. Vorontsov-Velyaminov: On the tidal origin of M51-type systems

V. Dostal and V. Metlov: The frequency of ring galaxies and the probability of their formation by collisions

P. Biermann and R. Wielen: Encounters of spherical galaxies: $\mathrm{N}$-body simulations and comparison with theoretical predictions

D. LYNDEN-BELL: ON THE MAGELLANIC STREAM, THE MASS OF THE GALAXY AND THE AGE OF THE UNIVERSE

W. E. Kunkel: The stellar component of the Magellanic Stream

A. G. D. Philip and A. G. Davis: Fine structure in the Magellanic Stream

\section{CLUSTERS OF GALAXIES}

J. Melnick, S. White and J. Hoessel: Photoelectric surface photometry of the Coma Cluster

C. LARI and G. C. PEROLA: RADIO PROPERTIES OF ABELL CLUSTERS

R. D. EKERS: RADIO OBSERVATIONS OF CLUSTERS OF GALAXIES: THE TAIL SOURCES

E. A. Valentijn and $H$. van der Laan: Extended radio emission in clusters of galaxies: recent Westerbork observations

R. Wielebinski: Clusters with extended radio emission at high frequencies 
V. L. Ginzburg: Radio haloes around galaxies and in clusters

J. L. CULHANE: X-RAY OBSERVATIONS OF CLUSTERS OF GALAXIES

J. SILK: GAS IN GALAXY CLUSTERS

S. J. AARSETH: COMPUTER SIMULATIONS OF GALAXY CLUSTERING

G. Paál: An analogy between simulated and actual clusters of different kinds

F. W. Baier: Structures and number-density distributions in clusters of galaxies

J. Burczyk and A. Zieba: Mathematical approach to the problem of clustering

A. Michalec and J. Machalski: Radio emission of Abel1 clusters in the $\mathrm{GB}$ and $\mathrm{GB} 2$ regions

\section{LARGE SCALE SYSTEMS}

G. DE VAUCOULEURS: THE LOCAL SUPERCLUSTER

R. B. Tully and J. R. Fisher: A tour of the Local Supercluster

P. J. E. PEEBLES: LARGE SCALE CLUSTERING IN THE UNIVERSE

L. Grishchuk: The isotropy of the universe on scales exceeding the horizon

K. RUDNICKI and S. ZIEBA: RESULTS ON THE LARGE SCALE DISTRIBUTION OF EXTRAGALACTIC OBJECTS OBTAINED BY THE METHOD OF STATISTICAL REDUCTION

M. JÔEVEER and J. EINASTO: HAS THE UNIVERSE THE CELL STRUCTURE?

G. 0. ABELL: THE PHYSICAL PROPERTIES OF LARGE SCALE SYSTEMS FROM OPTICAL OBSERVATIONS

M. Tarenghi, W. G. Tifft, G. Chincarini, H. J. Rood and L. A. Thompson: The structure of the Hercules supercluster

W. G. Tifft and S. A. Gregory: Observations of the large scale distribution of galaxies

J. Huchra: The field luminosity function and nearby groups of galaxies 
M. A. Arakelian: Markarian galaxies in the vicinity of the Coma cluster

P. Flin and M. Urbanik: Remarks on the angular distribution of Markarian galaxies

M. Kalinkov, V. Dermendjiev, B. Staikov, I. Kaneva, B. Tomov and K. Stavrev: Superclustering of galaxies

B. I. Fessenko: On the methods of discovering groups and clusters of galaxies

S. Phillipps: The autocorrelation analysis of deep galaxy samples

DISCUSSION OF METHODS ON DETERMINING THE MEAN MATTER DENSITY OF THE UNIVERSE

IV. OBSERVATIONAL EVIDENCE FOR COSMOLOGICAL EVOLUTION

M. SCHMIDT: QUASARS AND COSMOLOGICAL EVOLUTION

J. G. BOLTON and A. SAVAGE: THE SURFACE DENSITY OF QUASARS

H. Lorenz: A survey programme for QSO and related objects

M. S. LONGAIR: THE LARGE SCALE DISTRIBUTION OF RADIO SOURCES

Y. N. PARIJSKIJ: SEARCH FOR PRIMORDIAL PERTURBATIONS OF THE UNIVERSE: OBSERVATIONS WITH RATAN-600 RADIO TELESCOPE

P. E. BOYNTON: THE QUEST FOR FINE-SCALE ANISOTROPY IN THE RELICT RADIATION

H. GURSKY: COSMOLOGICAL INFORMATION FROM X-RAY OBSERVATIONS

I. D. Karachentsev and A. I. Kopylov: Counts of faint galaxies

B. M. TINSLEY: THE EVOLUTION OF GALAXIES: EVIDENCE FROM OPTICAL OBSERVATIONS

J. P. OSTRIKER: ON THE DYNAMICAL EVOLUTION OF CLUSTERS OF GALAXIES

B. J. T. JONES and M. J. REES: THE EPOCH OF GALAXY FORMATION

B. A. Peterson: QSO absorption lines and intergalactic hydrogen clouds 
R. A. SUNYAEV: FLUCTUATIONS OF THE MICROWAVE BACKGROUND RADIATION

A. A. Kurskov and L. M. Ozernoy: Constraints on the mean density of the Universe which follow from the theories of adiabatic and whirl perturbations

P. Boynton: Recent advances in microwave cosmology

\section{THE FORMATION OF STRUCTURE IN THE UNIVERSE}

YA. B. ZELDOVICH: THE THEORY OF THE LARGE SCALE STRUCTURE OF THE UNIVERSE

A. G. Doroshkevich, E. M. Saar and S.F. Shandarin: The internal structure of protoclusters and the formation of galaxies

L. M. OZERNOY: THE WHIRL THEORY OF THE ORIGIN OF STRUCTURE IN THE UNIVERSE

A. D. Chernin: Origin of protogalactic eddies

M. Davis: Evidence for the gravitational instability picture in a dense Universe

E. M. Kellogg: Primeval clusters of galaxies and the X-ray background

R. D. Davies: Observational limits on neutral hydrogen in primordial protoclusters

J. Jaaniste and E. Saar: Orientation of spiral galaxies as a test of theories of galaxy formation

A. M. Fridman: Non-1inear effects in flat gravitating systems

M. S. LONGAIR: PERSONAL VIEW - THE LARGE SCALE STRUCTURE OF THE UNIVERSE 